\title{
INITIAL EXPERIENCE OF RADICAL HYSTERECTOMY FOR EARLY CERVICAL CANCER AT A CANCER HOSPITAL IN NEPAL
}

\section{ABSTRACT}

The purpose of this study was to find out the clinocopathologic characteristics, post-operative findings and complications of patients with early (up to stage IIA) cervical carcinoma who underwent radical hysterectomy. This study concentrates on the evaluation of our early experience in radical hysterectomy for cervical cancer in Nepal. This was a retrospective analysis of 48 patients who had radical hysterectomy with bilateral pelvic lymphadenectomy for early cervical cancer at the BP Koirala Memorial Cancer Hospital (BPKMCH) from September 1999 through September 2002. Characteristics such as chief complaint, disease staging and duration, intraoperative and postoperative complications, histopathological findings, need for blood transfusion, and duration of hospital stay were considered for analysis. Patients' age ranged from 28-67 years. Age group of $40-49$ had highest number of patients (58.3\%). Majority (62.5\%) were premenopausal women who presented with abnormal vaginal bleeding (73\%) as the chief complaint. More than half of them (56\%) had FIGO stage IIA disease. Thirty-three percent had intraoperative and postoperative complications such as urinary problems, wound infection and vessel injury/ureteric injury. All needed blood transfusion, $\mathbf{4 2 \%}$ needing four pints. The average duration of hospital stay was 11 days. Forty-four had squamous cell carcinoma and four had adenocarcinoma. Pelvic lymph node metastasis was found in 10 patients. Resected margins were adequate in 42 patients. Majority $(62.5 \%)$ of the women were premenopausal and 56\% of them had stage IIA disease. Although the primary treatment of early-stage cervical carcinoma involves either surgery or radiation therapy with or without chemotherapy, surgery (radical hysterectomy) was used for lower-stage disease and smaller lesions in fit and young patients in our resource-poor set-up. Fifteen patients needed postoperative radiation. The complication rate seems to be higher in Nepal; however, it will decrease as more experience is gained.

Key Words: Cervical cancer, gynecological malignancies, human papillomavirus, radical hysterectomy.

\section{INTRODUCTION}

Cervical cancer is ranked as the third most common cancer in women worldwide (after lung and breast). ${ }^{1}$ Seventy eight percent of cases occur in developing countries, where cervical cancer is the second most frequent cause of cancer death in women. ${ }^{2}$

The incidence rates can vary more considerably between different population and geographic localities; for example, in Israel it is 12 per 100,000 and in Columbia it is 180 per $100,000 .{ }^{3}$ We do not have the incidence rate for Nepal.

Human papillomavirus (HPV) is considered to be the most important factor contributing to the development of cervical cancer. ${ }^{4}$ Many studies convincingly demonstrate that the major risk factor for development of preinvasive or invasive carcinoma of the cervix is HPV infection, which far outweighs other known risk factors such as high parity, increasing number of sexual partners, young age at first intercourse, low

Address for correspondence : Dr. Ganesh Dangal 
socioeconomic status, and positive smoking history. ${ }^{4,5}$

Other risk factors include history of sexually transmitted diseases, smoking, partners who have had multiple sexual partners, history of dysplasia of the cervix, vagina, or vulva. ${ }^{6-}$ ${ }^{10}$ The risk of cervical cancer is also increased in patients who are immunosuppressed. ${ }^{11-13}$

Signs and symptoms of early disease include watery vaginal discharge, intermittent spotting, and postcoital bleeding, although the symptoms may go unrecognised by patients. Accurate diagnosis may be made with cytology screening, colposcopically-directed biopsy, biopsy of a gross or palpable lesion, or cone biopsy to detect microinvasion or early stage carcinoma. ${ }^{14}$ But, in Nepal cytologic screening and colposcopy are not available for all and are rarely performed.

Management of early cervical carcinoma involves surgery or radiation therapy with or without chemotherapy. Surgical treatment is preferred for young women with small tumors because it permits preservation of ovarian function and causes minimal vaginal shortening unlike significant fibrosis and narrowing/shortening of the vagina with the use of radiation. Radical hysterectomy and bilateral pelvic lymphadenectomy has been considered standard surgical treatment. ${ }^{15}$

The aim of this study was to evaluate our experience of surgical therapy for early cervical carcinoma at the BP Koirala Memorial Cancer Hospital, Nepal.

\section{PATIENTS AND METHODS}

This is a retrospective study of 48 patients who have undergone radical hysterectomy and bilateral pelvic lymphadenectomy for early stage cervical carcinoma (stage I and IIA) from
September 1999 through September 2002. The study was performed using the hospital records of patients treated at the Gynecological Oncology Unit at the BP Koirala Memorial Cancer Hospital.

Radical hysterectomy with bilateral pelvic lymphadenectomy was performed for all of the patients: fifteen young patients had ovarian conservation. The extension of lymph node dissection consisted of the common iliac, internal iliac, external iliac, and obturator groups of lymph nodes. Pelvic drainage through the vaginal vault by placing a latex glove drain was performed. All the patients received prophylactic antibiotic (Inj. cefazolin) and aseptic technique was observed for the surgeries.

Patients' age, chief complaint, clinical stage and disease duration, histological types of the tumor, status of pelvic lymph node metastases, condition of the resected vaginal margin, associated complications, need for blood transfusion, and duration of hospital stay were analyzed. Postoperative followup could not be done, so we lack data on this aspect.

\section{RESULTS}

Patients' age ranged from 28-67 years (mean, 45 years) [Table I]. Majority of the patients were premenopausal women $(62.5 \%)$. All were multiparous. The chief complaints were abnormal vaginal bleeding, abnormal vaginal discharge, and lower abdominal pain [Table II]. Duration of disease (from the onset of symptoms to the diagnosis of the disease) was 1 to 26 months (median, 5 months) [Table III].

Of the 48 patients, $44(92 \%)$ had squamous cell carcinoma and $4(8 \%)$ had adenocarcinoma. The largest group of patients was those with stage IIA disease (FIGO Classification),

Table I : Age distribution of the patients

\begin{tabular}{c|c|c|cc|c}
\hline Age (years) & $<40$ & $\mathbf{4 0 - 4 9}$ & $\mathbf{5 0 - 5 9}$ & $>\mathbf{6 0}$ & Total \\
\hline Number of patients & $9(18.7)$ & $28(58.3)$ & $10(20.8)$ & $1(2.1)$ & $48(100)$ \\
\hline
\end{tabular}

Figures in parenthesis are the percentages

Table II : Chief complaint of the patients

\begin{tabular}{l|c}
\hline \multicolumn{1}{c|}{ Chief complaints } & Number of patients \\
\hline Abnormal vaginal bleeding & $35(72.9)$ \\
\hline Abnormal vaginal discharge & $8(16.7)$ \\
Lower abdominal pain & $5(10.4)$
\end{tabular}

Figures in parenthesis are the percentages

Table III : Duration of the disease (from onset to diagnosis)

\begin{tabular}{c|ccc|c}
\hline Duration (months) & $<6$ & $6-12$ & $>12$ & Total \\
\hline Number of patients & $30(62.5)$ & $16(33.3)$ & $2(4.2)$ & $\mathbf{4 8 ( 1 0 0 )}$ \\
\hline
\end{tabular}

Figures in parenthesis are the percentages 
Table IV : Clinicopathological FIGO staging of patients with cervical cancer

\begin{tabular}{c|c}
\hline Stage & Number of patients \\
\hline IA1 & $1(2.1)$ \\
\hline IA2 & $1(2.1)$ \\
\hline IB1 & $10(20.8)$ \\
\hline IB2 & $6(12.5)$ \\
\hline IIA & $27(56.3)$ \\
\hline IIB & $3(6.3)$ \\
\hline
\end{tabular}

Abbreviation: FIGO = International Federation of Gynecology and Obstetrics

Figures in parenthesis are the percentages

Table V : Status of the resected margins of the tumor

\begin{tabular}{|c|c|}
\hline Margin & Number of patients \\
\hline Negative* $^{*}$ & $42(87.5)$ \\
\hline Close to tumor $^{\dagger}$ & $4(8.3)$ \\
\hline Positive $\ddagger$ & $2(4.2)$ \\
\hline Total & $48(100)$ \\
\hline
\end{tabular}

Figures in parenthesis are the percentages

* Free margin >5 mm with no microscopic involvement.

${ }^{\dagger}$ Margin $<5$ mm but no microscopic involvement.

$\$$ Microscopic involvement of the surgical margin.

Table VI : Complications of radical hysterectomy

\begin{tabular}{l|c}
\hline \multicolumn{1}{c|}{ Complication } & Number of patients \\
\hline Vessel injury (Laceration of Pelvic veins) & $4(8.3)$ \\
\hline Ureteric injury & $1(2.1)$ \\
\hline Urinary tract infection & $2(4.2)$ \\
\hline Urinary bladder dysfunction & $2(4.2)$ \\
\hline Vault bleeding & $2(4.2)$ \\
\hline Wound infection & $4(8.3)$ \\
\hline Lymphocyst formation & $1(2.1)$ \\
\hline No complication & $32(66.7)$ \\
\hline
\end{tabular}

Figures in parenthesis are the percentages

accounting for $56 \%$ of all patients [Table IV]. Three patients who were initially presumed to be in stage IIA turned out to be in stage IIB. The results would have changed if these patients were not included. Ten of 48 patients had lymphatic spread (21\%). Resected margins were adequate in $87.5 \%$ of the patients [Table V].

The patients whose resected margins were positive or close to the tumor also had positive groin nodes. They (15 patients) were treated with postoperative radiotherapy.

Eighteen patients had intraoperative or postoperative complications, accounting for $33 \%$ of the patients and most of them were minor problems [Table VI]. There was no mortality.

All of the patients needed blood transfusion before, during, or after the operation, $42 \%$ needing four pints. The average duration of hospital stay was 11 days.

\section{DISCUSSION}

Cervical cancer incidence and mortality have fallen substantially in recent years in the industrialized world. But in Nepal, where routine screening is not practiced, the disease remains largely uncontrolled. Although cervical cancer is largely a preventable disease, it continues to be a leading cause of cancer death for women in many developing countries such as Latin America, southern and eastern Africa, India, and Polynesia. ${ }^{16}$ According to a recent study, the incidence of cervical carcinoma is high in Mexico $(17.1 / 100,000)$, Venezuela (15.2/100,000), and Tobago (15.0/100,000). ${ }^{17}$

Nepal does not have its own data on the incidence of cervical carcinoma; probably early marriage, early childbearing, and multiparity predispose women to the disease in this country. As there is no mass screening programs in Nepal, it is difficult to know the HPV prevalence here. Unfortunately we also do 
not have any authentic data on the risk factors for cervical cancer.

Although cervical cancer is associated with a broad age range, it usually occurs in the fifth or sixth decade, at a mean age of 54 years. ${ }^{18}$ In a study at the BP Koirala Memorial Cancer Hospital, 272 cases of cervical carcinoma were diagnosed, which accounted for $84.73 \%$ of 321 gynecological malignancies and $31.16 \%$ of all 873 cancers. ${ }^{19}$ And the highest incidence was among the 31 to 50 years age group. This is in concordance with our finding that the mean age was 45 years.

Of all cervical cancers, $85-90 \%$ are squamous cell carcinoma. ${ }^{20}$ In this series, of the 48 patients, $44(92 \%)$ had squamous cell carcinoma and four $(8 \%)$ had adenocarcinoma.

Surgical therapy and radiotherapy are the two main treatment modalities for carcinoma of the cervix. From a clinical perspective, cervical cancer is readily managed in its early stages by surgery, with radiation or chemoradiation therapy reserved for high-risk early or advanced stages.

Early invasive disease (stages IA2, IB1, and small stage IIA) is managed with radical hysterectomy or radiation therapy, which results in a 5 -year survival rate of $80 \%-90 \% .^{21}$

The optimal treatment for most patients with Stage IIA cervical cancer is radiation therapy consisting of a combination of externaland intracavitary therapy. However, patients can also be treated effectively by radical hysterectomy with pelvic and para-aortic lymphadenectomy and upper vaginectomy, provided that adequate surgical margins can be obtained.

In patients undergoing radical hysterectomy for stage IB cervical cancer, metastasis to the pelvic lymph nodes is found in $15-20 \% .^{22,23}$ In a recent European study of patients undergoing radical hysterectomy for early cervical cancer, lymph node metastasis rate was $22 \% .^{24}$ In this series, the lymph node metastasis rate was $21 \%$ that is not much different from what is expected for stage I and IIA disease (4.3\% to $34.0 \%){ }^{25,26}$

Concurrent chemoradiation (cisplatinum $40 \mathrm{mg} / \mathrm{m}^{2}$ and 5 flurouracil $1000 \mathrm{mg} / \mathrm{m}^{2}$ ) is the standard of care for locally advanced cancers of cervix in some centers. ${ }^{27,28}$ In Nepal, cisplatin only (for chemoradiation) is used in most centers.

In a large European study of patients undergoing radical hysterectomy for early cervical cancer, post-operative mortality was < $1 \%$; urinary tract infection was $42 \%$; deep venous thrombosis was $3 \%$; and fistula was $2 \% .{ }^{24}$
In another study, seven percent of the patients undergoing radical hysterectomy exhibited intraoperative complications and $35 \%$ suffered from early postoperative urinary tract problems; most frequently urinary tract infection. ${ }^{29}$

In this series, eighteen patients had intraoperative or postoperative complications, accounting for $33 \%$ of the patients and most of them were minor problems. There was no operative mortality. The patients whose resected margins were positive ( 2 cases) or close to the tumor ( 4 cases) were treated with adjuvant concurrent chemoradiation. In cases of large stage IIA/B disease adequate surgical margins could not be obtained. With proper case selection and management, the margin positivity will be reduced in the future.

Technical competency will improve in the future and thereby leads to the reduction in vessel injuries/lacerations, other complications and resected margin positivity.

There seems to be a rather high rate of complications, especially the requirement for transfusion in all patients undergoing surgery. This may be due to the fact that most of the patients had stage IIA disease. And their nutritional status and hemoglobin $(\mathrm{Hb})$ level was not optimum $(\mathrm{Hb}$ was around 10 gm \%). A longer hospital stay was partly because of this and also by the practice( in our hospital) of admitting patients two days before surgery for preoperative evaluation.

Although surgery and radiation therapy produce similar survival rates, radical hysterectomy is considered by many to be the treatment of choice for young, healthy patients with IB1 lesions. ${ }^{30,31}$ Excellent survival rates can be achieved in these patients along with preservation of ovarian and sexual functions.

In clinical circumstances where survival rates after treatment are equivalent, radical hysterectomy has advantages over radiotherapy. Therefore, for Nepalese women with early cervical cancer the primary treatment option is considered to be surgical excision rather than radiotherapy. This is partly because of the availability of the surgical expertise in the country and surgery here is cheaper as opposed to the radiation therapy, which is of longer duration and demands more financial resources. In addition, surgery preserves the ovarian function, permits a comprehensive surgical staging of the extent of disease, avoids the chronic bowel and bladder problems of radiation and also maintains the vaginal canal in young patients unlike radiation therapy thereby maintaining the quality of the psychosexual component of the patients' life. ${ }^{32,33}$ Furthermore, surgical and pathologic data fromradical 
surgery are important for precise analysis of survival and prognostic risk factors. On the other hand, the radical hysterectomy procedure carries possible morbidity similar to that encountered with other major pelvic operations, but this acknowledged, if the operation is properly performed, it is safe and effective. ${ }^{14}$

\section{CONCLUSION}

The primary treatment of early-stage cervical carcinoma involves either surgery or radiation therapy, with or without chemotherapy. The selection of either option depends on patient factors and available local expertise. A radical hysterectomy and removal of the pelvic lymph nodes is most commonly used to treat stage I or stage IIA cervical cancers in our set-up. In Nepal, radical surgery was found to be valuable in fit and young patients with lower-stage disease and smaller lesions.

\section{ACKNOWLEDGEMENTS}

I would like to thank my colleagues at the BP Koirala Memorial Cancer Hospital for their kind help and all the staff of the Gynecological Oncology and Pathology Departments. I thank the hospital authority for allowing me to carry out this study. My special thanks go to Prof Dr FP Neupane for meticulously editing the manuscript and providing important advice. My sincere thanks are also due to my wife Reshma and son Ojash for their various supports to me during the preparation of the manuscript of this paper.

\section{REFERENCES}

1. Parkin DM, Pisani P, Ferlay J. Global cancer statistics. CA Cancer J Clin 1999; 49: 33-64.

2 Boffetta P, Parkin DM. Cancer in developing countries. CA Cancer J Clin 1994; 44: 81-90.

3. Glass RH, ed.. Office Gynecology, $3^{\text {rd }}$ edition. Baltimore: Wi 7 liams and Wilkins; 1988: 98.

4. Schiffman $M H$, Bauer $H M$, Hoover RN, Glass AG, Cadell DM, Rush BB, et al. Epidemiologic evidence showing that human papillomavirus infection causes most cervical intraepithelial neoplasia. J Nat I Cancer Inst 1993; 85: 958-64.

5. Brisson J, Morin C, Fortier M, Roy M, Bouchard C, Leclerc J, et al. Risk factors for cervical intraepithelial neoplasia: differences between low- and high-grade lesions. Am J Epidemiol 1994; 140 (8) : 700-710.

6. Devesa SS. Descriptive epidemiology of cancer of the uterine cervix. Obstet Gynecol 1984; 63:605.

7. Christopherson WM, Parker JE. Relation of cervical cancer to early marriage and childbearing. N Engl J Med 1965; 273: 235-239.
8. Winkelstein W Jr. Smoking and cervical cancer-current status: a review. Am J Epidemiol 1990; 131: 945-957.

9. Rotkin ID. Epidemiology of cancer of the cervix. Sexual characteristics of a cervical cancer population. Am J Public Health Nations Health 1967; 57: 815-829.

10. Kessler II. Human cervical cancer as a venereal disease. Cancer Res 1976; 36: 783-791.

11. Schneider V, Kay S, Lee HM. Immunosuppression as a highrisk factor in the development of condyloma acuminatum and squamous neoplasia of the cervix. Acta Cytol 1983; 27: 220224 .

12. Katz RL, Veanattukalathil S, Weiss KM. Human papillomavirus infection and neoplasia of the cervix and anogenital region in women with Hodgkin's disease. Acta Cytol 1987; 31: 845-854.

13. Klein RS, Ho GYF, Vermund SH, Fleming I, Burk RD. Risk factors for squamous intraepithelial lesions on Pap smear in women at risk for human immunodeficiency virus infection. J Infect Dis 1994; 170: 1404-1409.

14. Hatch KD, Fu YS. Cervical and vaginal cancer. In: Berek JS, Adashi EY, Hillard PA, eds. Novak's Gynecology, 12th edition. Balitimore: Williams and Wilkins; 1996: 1111-1153.

15. Eifel PI, Berek JS, Thigpen JT. Cancer of the cervix, vagina, and vulva. In: DeVita VT, Hellman S, Rosenberg SA, eds. Cancer: principles and practice of oncology. 6th edition. New York:Lippincott Williams and Wilkins; 2001: 1526-1573.

16. Parkin DM, Pisani P, Ferlay J. Estimates of the worldwide incidence of 25 major cancer in 1990. Int J Cancer 1999; 80 : $827-841$.

17. Jemal A, Thomas A, Murray T, Thun M. Cancer statistics, 2002. CA Cancer J Clin 2002; 52: 23-47.

18. Barber HRK. Incidence, prevalence, and median survival rates of gynecologic cancer. In: Van Nagell JR, Barber HRK, eds. Modern concepts of gynecologic oncology. Boston: John Wright-PSG; 1982: 1-19.

19. Pradhan M, Dhakal HP, Pun CB, Pradhan S, Dangal G. Gynecological malignancy in BPKMCH, Bharatpur: a retrospective analysis of 321 cases. J Nepal Med Assoc 2001; 40: 108-111.

20. Scott JR, Di Saia PJ, Hammond CB, Spellacy WN, eds. Danforth's Costetrics and Gynecology, $6^{\text {th }}$ edition. Philadelphia: JB Lippincott Co.; 1990:1002.

21. Cannistra SA, Niloff JM. Cancer of the uterine cervix. NEngl $J$ Med 1996; 334: 1030-1038.

22. Van Bommel PF, van Lindert AC, Kock HC, Leers $\mathrm{WH}$, Neijt JP. A review of prognostic factors in early-stage carcinoma of the cervix (FICO IB and IIA) and implications for treatment strategy. Eur J Obstet Gynecol Reprod Biol 1987; 26: 69-84.

23. Fuller AF Jr, Elliott N, Kosloff C, Lewis J Jr. Lymph node metastases from carcinoma of the cervix, stages IB and IIA: implications for prognosis and treatment. Gynecol Oncol 1982; 13: $165-74$. 
24. Trimbos JB, Franchi M, Zanaboni F, Velden J, Vergote I. 'State of the art' of radical hysterectany; arrent practice in European oncology centres. Eur J Cancer 2004; 40 (3) : 375-378.

25. Piver MS, Chung WS. Prognostic significance of cervical lesion size and pelvic node metastases in cervical carcinoma. Obstet Gynecol 1975; 46:507-510.

26. Shinglelon HM, Thompson JD. Cancer of the cervix. In: Rock JA, Thompson JD, eds. Operative gynecology, 8th edition. New York: Lippincott-Raven; 1997: 1413-1499.

27. Morris M, Eifel PJ, Lu J, Grigsby PW, Levenback C, Stevens $\mathrm{RE}$, et al. Pelvic radiation with concurrent chemotherapy compared with pelvic and para-aortic radiation for high-risk cervical cancer. $N$ Engl J Med 1999; 340:1137-1143.

28. Rose PG, Bundy BN, Watkins EB, Thigpen JT, Deppe G, Maiman MA, et al. Concurrent cisplatin-based radiotherapy and chemotherapy for locally advanced cervical cancer. $N$ Engl $J$ Med 1999; 340:1144-1153.
29. Gerdin E, Cnattingius S, Johnson P. Complications after radiotherapy and radical hysterectomy in early-stage cervical carcinoma. Acta Obstet Gynecol Scand 1995; 74 (7) : 554-61.

30. Medical practice and ethics committee. Management of gynecologic cancers, in society of gynecologic oncologists clinical practice guidelines. Chicago: Society of Gynecologic Oncologists; 1996: 34-43.

31. Averette $H E$, Nguyen $H N$, Donato DM, Penalver MA, Sevin BU, Estape R, et al. Radical hysterectomy for invasive cervical cancer. A 25-year prospective experience with the Miami technique. Cancer 1993; 71:1422-1437.

32. Seibel MM, Freeman MG, Graves WL Carcinoma of the cervix and sexual function. Obstet Gynecol 1980; 55: 484-487.

33. Seibel MM, Freeman MG, Graves WL The effect of surgical and radiation treatment for cervical carcinoma on sexual function. South Med J 1982; 75:1195.

$$
\text { Lstes }
$$

\title{
$5^{\text {th }}$ Conference
}

\section{South Asian Federation of}

\section{Obstetricians \& Gynaecologists}

\author{
Theme : Challenges of Community Obstetrics in South Asian Region
}

Date $: 2^{\text {th }}-5^{\text {th }}$ June, 2005

Venue : Soaltee Crowne Plaza Hotel
Tahachal, Kathmandu, Nepal

Contact Address:

Nepal Society of Obstetricians \& Gynaecologists

Maternity Hospital, Thapathali

G.P.O. Box: 10644, Kathmandu, Nepal

Tel: $977-1-4252315$

Fax: 977-1-4252315

Email: nesog@ccsl.com.np

Website: www.nesog.org.np 